\title{
Fabrication of Genetic Analysis Microsystems using Plastic Microcasting
}

\author{
P. Sethu, H. Yu ${ }^{\dagger}$, P. Grodzinski ${ }^{\dagger}$, and C. H. Mastrangelo \\ Center for Integrated Microsystems \\ Department of Electrical Engineering and Computer Science \\ University of Michigan, Ann Arbor, MI 48109-2122, USA \\ (734)-763-7162, FAX:(734)-763-9324 \\ $\dagger$ Microffuidics Laboratory, Motorola Labs. \\ 2100 East Elliot Road, MD EL508 \\ Tempe, AZ 85284, USA
}

\begin{abstract}
In this paper we present a simple, low cost, high resolution plastic microcasting method using two component, optically clear polymers for the fabrication of microfluidic systems. This method allows excellent replication of microfeatures $(<1 \mu \mathrm{m})$, low surface roughness $(<30$ $\mathrm{nm}$ ), the ability to embed devices, and the capability of mass production. Using this method we have successfully implemented plastic microsystems capable of separating and amplifying DNA. We present the first demonstration of plastic microreaction chambers with on-chip heaters and coolers and also the fabrication and demonstration of a microcapillary electrophoresis device made by this technique.
\end{abstract}

Keywords: plastic casting, capillary electrophoresis, microPCR, genetic analysis systems.

\section{INTRODUCTION}

Miniaturized systems for biochemical analysis can significantly reduce the cycle time, reagent cost and labor intensity compared to traditional technologies [1-3]. Many of these systems are targeted for a few or even single use assay applications where it is essential that they are fabricated using inexpensive materials and technologies. Devices for these microfluidic systems have been previously made by injection molding (IM) [4] and hot embossing [5]. Casting methods for microfluidic devices were initially introduced by Whitesides [6]. Plastic microcasting is a simple, low cost fabrication technique which uses liquid polymers which are poured in a micromold and cured to form solid parts. Unlike conventional IM methods, microcasting offers excellent replication resolution but so far it has been limited to silicon rubber materials and nonplanar substrates.

In this paper we have extended the microcasting process to more rigid and less permeable epoxy materials and we have developed practical methods for the production of planar plastic casted wafers that enable further lithographic processing. Since plastic microcasting uses liquid polymers, embedding of active devices in plastics can also be done relatively easily. Our process offers excellent replication resolution $(<1 \mu \mathrm{m})$, a high process flexibility using a wide variety of plastic materials, the ability to embed elements, and a low fabrication costs. Highquality sealed-channel devices are fabricated using a lamination process on top of microcasted structures. Both capillary electrophoresis and micro PCR devices with integrated heaters, coolers and temperature sensors were fabricated by microcasting.

\section{CASTING POLYMERS}

The best polymers for genetic analysis and microfluidic applications have low viscosities, high light transmission, good water barrier properties, chemical resistance to biological reagents, and stability at elevated temperatures (up to $100^{\circ} \mathrm{C}$ ). Common castable materials include acrylics, polyurethenes, fluoropolymers, silicone rubbers and epoxies. Maximum operating temperatures for acrylics and polyurethenes are below $80^{\circ} \mathrm{C}$. While the temperature and chemical resistance of fluoropolymers is excellent the light transmission is in general poor. Silicone rubbers are easily castable but have high water permeabilities [7] resulting in rapid sample loss. Epoxies offer high working temperatures, good chemical resistance, and good barrier properties (second only to fluoropolymers); therefore are the most suitable polymers for microfluidic applications.

For our applications, we selected low viscosity epoxies that were easily castable and provide an adequate working time before solidification. The epoxies used for fabricating the devices were EPOTEK 301-2 (Epoxy Technologies, Billerica, MA) with viscosity $300 \mathrm{cps}$, light transmission $98 \%$, water absorption (room temperature, $98 \%$ RH, 30 days) $1 \%$, and EPOTEK 301-2 FL, with viscosity $150 \mathrm{cps}$, light transmission 99\%, water absorption (room temperature, $98 \% \mathrm{RH}, 30$ days) $1.5 \%$. Both cpoxies have a maximum operating temperatures of $125^{\circ} \mathrm{C}$ and a curing time of 8 hours at $45^{\circ} \mathrm{C}$.

\section{CASTING PROCESS}

Figure 1 shows the simplified microcasting process. First, patterns for channels, reservoirs, chambers, and reactors are etched in a silicon wafer using a deep RIE system (Specialty Technology Systems), $\left(\mathrm{SF}_{6}: 130 \mathrm{sscm}\right.$, $\mathrm{O}_{2}: 30 \mathrm{sscm}, \mathrm{C}_{4} \mathrm{~F}_{8}: 80 \mathrm{sscm}$, coil power:800 Watts, and platen power:600 Watts, 30 mins.) Next, a $1 \mu \mathrm{m}$-thick p-xylylene (parylene-C) layer is vapor deposited on the patterned silicon substrate [8]. This thin film serves as a release layer which facilitates the separation between 


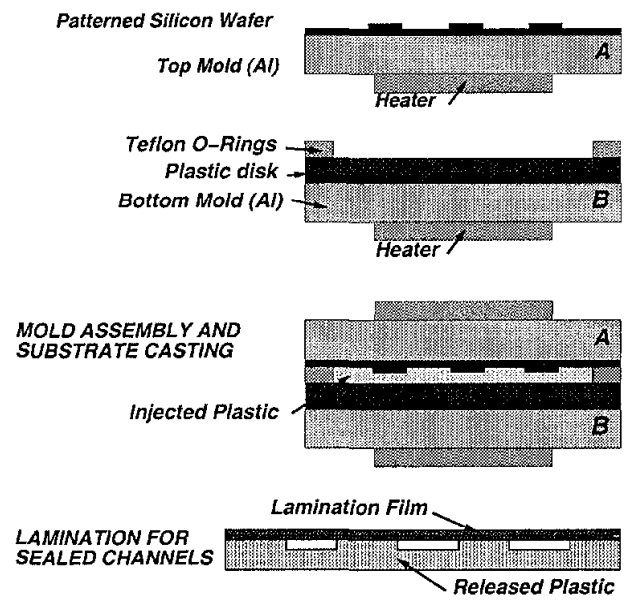

Figure 1: Microcasting and lamination process flow

the casted material and the wafer surface. The patterned silicon substrate is then used to create a mold by joining it with a supporting plastic plate and teflon ring spacer. The mold assembly is then placed between two aluminum molds as shown in Figure 2. The mold is then heated to $45^{\circ} \mathrm{C}$ for $8 \mathrm{hrs}$ and filled with a low viscosity catalysed epoxy (EPOTEK 301-2, EPOTEK 301-2 FL).

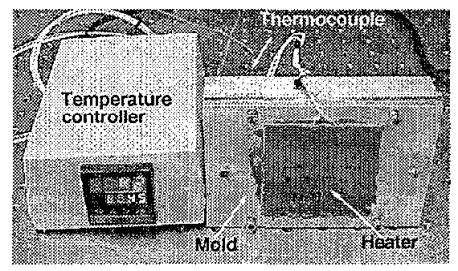

Figure 2: Complete mold setup with computer controlled heaters

Figures 3(a) and 3(b) show SEM photographs of a casted substrate $50 \mu \mathrm{m}$ deep with channels $100 \mu \mathrm{m}$ wide and reservoirs $5 \mathrm{~mm}$ wide showing the texture of the plastic surfaces which reproduce exactly the texture of the RIE etched molds (surface roughness $<30 \mathrm{~nm}$ ). Throughsubstrate access holes are created either using a two mold process which uses a plastic wafer with press fitted pins on one side or by drilling holes through the substrate.

\section{LAMINATION}

In order to seal channels and reservoirs, a flexible transparent film is laminated [9] on top of the epoxy substrates. The lamination process uses a desktop roll type laminator (Kepro Circuit Systems, Inc. BLT 121-A) and a thin mylar film (2 mil, Monokote, Top-Flite, Inc.) is used to laminate the plastic substrates. The substrate is first treated with acetone, and then the film is laminated onto the substrate by passing it between two rollers. The process is carried out at room temperature and at a feed rate of $2 \mathrm{ft} / \mathrm{min}$. Figure 4 shows the cross section of a laminated channel. These structures show excellent permeation barrier characteristics with water permeabilites $\mathrm{P}$

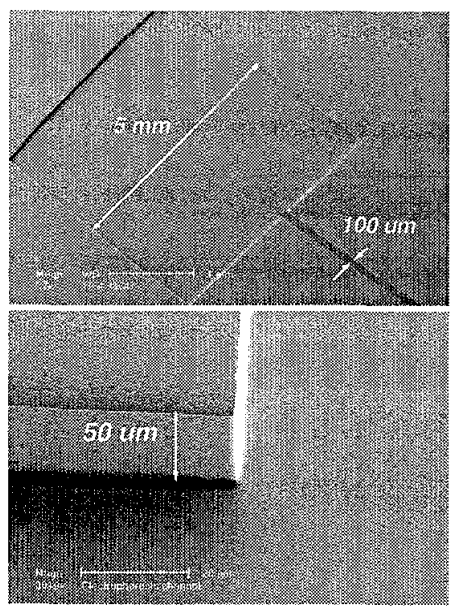

Figure 3: SEM images of (a) large-feature plastic casted microfluidic channel structures and (b) showing the side walls of the plastic casted microfluidic channel structures

$<1.7 \mu 1 / \mathrm{cm}^{2} /$ day at room temperature. When these capillaries are filled with sample there is no seeping present at the bond interface.

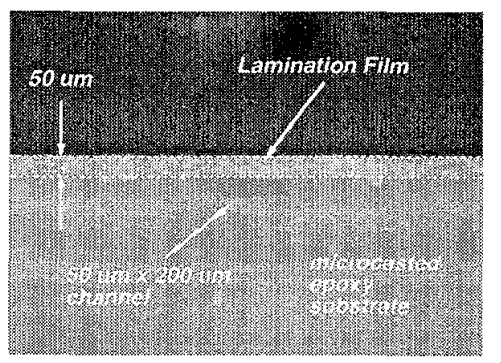

Figure 4: Cross section of a laminated channel

\section{PCR DEVICE FABRICATION}

A PCR device was fabricated using the casting process. The device is made by embedding pre-assembled components around a reaction chamber to obtain controlled heating and cooling cycles. The device consists of a reaction chamber which was made using a $1 \mathrm{~mm}$ diameter glass capillary (Laboratory Devices, Inc.), a resistive heating coil (Scientific Instrument services W73), a $4 \times$ $4 \times 2.2 \mathrm{~mm}^{3}$ thermoelectric (TE) cooler (Melcor), and a $250 \mu \mathrm{m}$ OD thermocouple (Omega Engineering, Inc.). The mold assembly for casting the PCR device is shown in Fig. 5

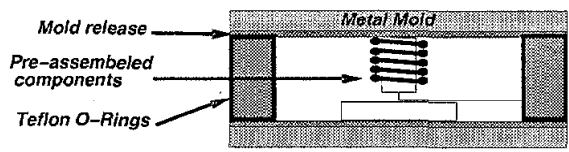

Figure 5: Mold assembly for casting the PCR device

These elements are assembled between a metal plate coated with a common injection molding release agent 
and another self releasing plastic disk. All of these components are pre-assembled before setting them in the mold and embedding them in cpoxy and cured. The heating coil was located around the glass capillary (reaction chamber), the TE cooler was located at the bottom of the glass capillary, and the thermocouple was placed between the glass capillary and the TE module with the tip in the bottom of the reaction chamber. Figures 6 shows a picture of the released PCR device.

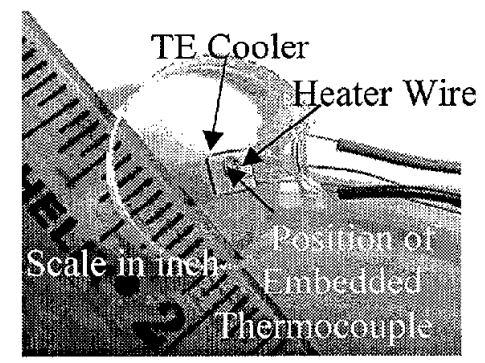

Figure 6: Photograph of micro PCR device

\section{PCR DEVICE CHARACTERIZATION AND RESULTS}

Automated temperature control was obtained using a programmed controller (PID loop, MOD30ML, from $\mathrm{ABB})$. The controller was connected to a $\mathrm{PC}$ running a custom graphical interface. The temperature feedback from the thermocouple at the bottom of the chamber was fed to the controller which controlled both the heaters and coolers. Heating was obtained using both the TE modules and the coil heaters and cooling was obtained using only the TE module.
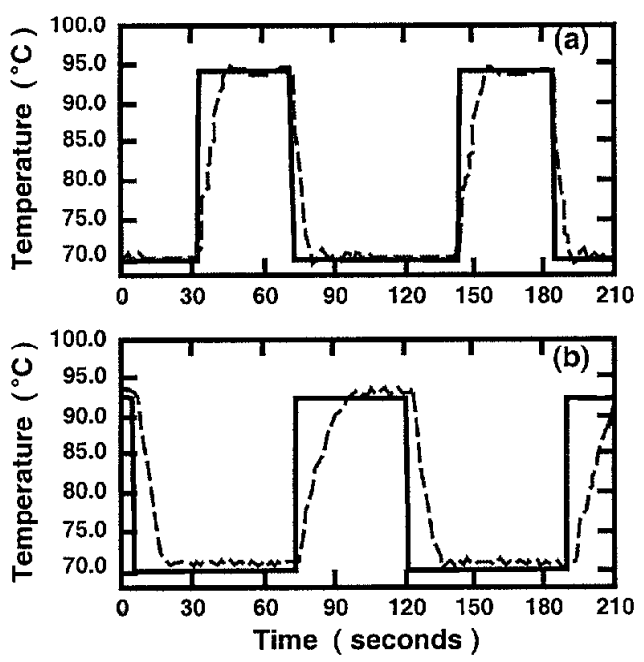

Figure 7: Thermal cycles obtained with the plastic microreaction chamber with a) both heating and TE module and b) only heating module

The heating and cooling rates were observed for a two-step temperature cycle $\left(94^{\circ} \mathrm{C}\right.$ for 30 seconds and $70^{\circ} \mathrm{C}$ for 60 seconds) for 24 cycles. When both the heating coils and the TE module were turned on, a heating rate of $2.4^{\circ} \mathrm{C} / \mathrm{s}$ and a cooling rate of $2.0^{\circ} \mathrm{C} / \mathrm{s}$ were obtained and when the TE module was turned off a heating rate of $1.0^{\circ} \mathrm{C} / \mathrm{s}$ and a cooling rate of $1.6^{\circ} \mathrm{C} / \mathrm{s}$ were obtained. The graph showing the heating and cooling cycles is shown in Figure 7

Escherichia Coli cells were first thermally lysed and then the released genomic DNA segments were amplified. Approximately two-thirds of E. coli bacterial colony was collected and resuspended in $50 \mu \mathrm{l}$ of sterile $\mathrm{H}_{2} \mathrm{O}$. Then this suspension was diluted $1: 10$ in a $\mathrm{PCR}$ reaction mixture containing $10 \mathrm{mM}$ Tris-HCL (pH 8.3), 50 $\mathrm{mM} \mathrm{KCL}, 1.5 \mathrm{mM} \mathrm{MgCl} 2,0.0001 \%$ gelatin, $250 \mathrm{~g} / \mathrm{ml}$ bovine serum albumin, $200 \mu \mathrm{M}$ each deoxynucleotide triphospate, $1.0 \mu \mathrm{M}$ each primer, 2.5 units $/ 100 \mu \mathrm{Ampli}$ Taq DNA polymerase. $1.5 \mu \mathrm{l}$ of the mixture is loaded in the reaction chamber and is topped off with liquid wax to prevent evaporation of the sample. Cell lysis was done at $94^{\circ} \mathrm{C}$ for 1 minute and then thermally cycled at $50^{\circ} \mathrm{C}$ for $30 \mathrm{~s}$ and $72^{\circ} \mathrm{C}$ for 30 seconds for 25 cycles. The primer set used to amplify a 346-bp segment of E. coli lamB gene was 5'-CTG ATC GAA TGG CTG CCA GGC TCC-3' and 5'-CAA CCA GAC GAT AGT TAT CAC GCA-3'. Then the amplified product obtained using this device was compared with the one obtained using a conventional thermal cycler. Figure 8 shows the results of gel electrophoresis on both the amplified products.

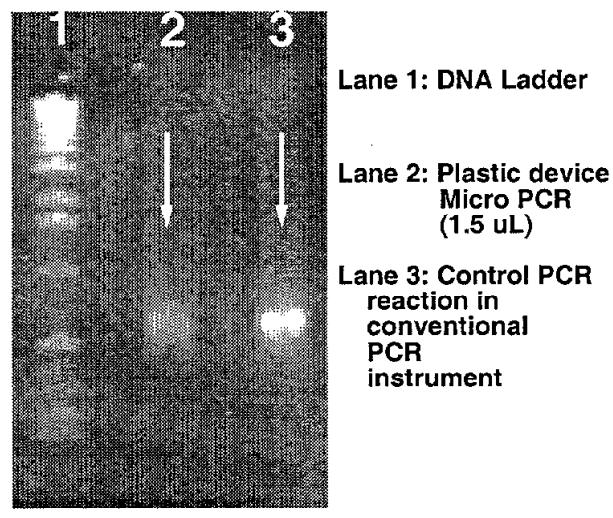

Figure 8: Separations obtained by gel electrophoresis after on-chip and off-chip PCR

\section{CAPILLARY ELECTROPHORESIS DEVICE}

Devices for capillary electrophoresis can be easily made using the casting process. A silicon wafer with a photoresist (Microposit SC1827) mask is etched using a deep RIE to get the profiles required to form the channels (50 $\mu \mathrm{m}$ deep and $100 \mu \mathrm{m}$ wide). The separation chanmel is 3 $\mathrm{cm}$ long and the reservoir dimensions are $5 \times 5 \mathrm{~mm}^{2}$. The channels for sample introduction are $0.5 \mathrm{~cm}$ long. Figure 9 shows a fabricated capillary electrophoresis device.

\section{CAPILLARY ELECTROPHORESIS RESULTS}

The fabricated capillary electrophoresis devices were used to perform separations using a $0.5 \%(\mathrm{w} / \mathrm{v})$ hydrox- 


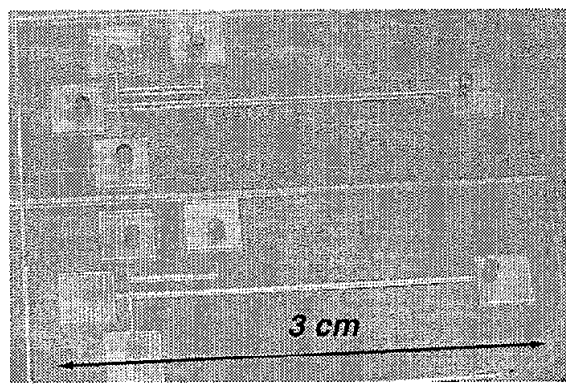

Figure 9: Microscope picture of a fabricated Capillary electrophoresis device with separation channels and reagent reservoirs

yethylcelluose (HEC) (MW 90,000-105,000) sieving matrix. Approximately $3 \mu$ of the electrophoresis buffer $(0.2 \mathrm{~g}$ HEC, $4 \mathrm{ml}$ of $1 \mathrm{x}$ TBE buffer, and $36 \mathrm{ml}$ of distilled, DI water) was introduced in the analyte waste reservoir using a stiff needle syringe. After the channels have filled completely due to capillary action, the other reservoirs are filled with the buffer and the analyte reservoir is filled with $0.5 \times$ TBE.

Pre-electrophoresis was done by applying $300 \mathrm{~V} / \mathrm{cm}$ across the separation channel for 10 minutes and keeping the analyte and analyte waste reservoirs at a potential of 0 $\mathrm{V}$. This is done to produce a concentration gradient in the HEC while increacing the concentration of HEC in the column above $0.5 \%$. Approximately $2 \mu \mathrm{l}$ of a DNA sample labeled with SYBR Green I at an intercalating ratio of greater than 1:5, dye:DNA bp is loaded into the injection reservoir. Samples were then separated under an electric field of $110 \mathrm{~V} / \mathrm{cm}$ in a distance of $3 \mathrm{~cm}$. Figure 10 shows the DNA plug and scparations obtained using the plastic capillary electrophoresis devices. The plastic has very low background fluorcscence and does not interfere with the fluorescence of the DNA bands.
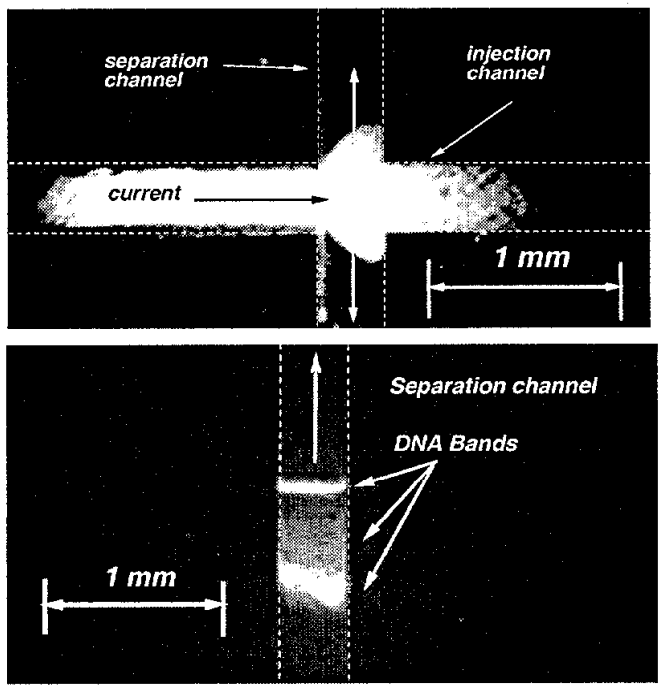

Figure 10: Images of (a) Injection plug and (b) DNA bands obtained by capillary electrophoresis

\section{SUMMARY}

We have presented a low cost casting method for the fabrication of microfludic devices. Using this casting method we have developed devices for genetic analysis applications like PCR and capillary electrophoresis. We have also have demonstrated working devices with measured results.

\section{ACKNOWLEDGMENTS}

The authors thank Mr. Jun Zheng for testing the capillary electrophoresis devices. This work was supported by the DARPA MEMS program under the contract F3060298-2-0197.

\section{References}

[1] A. T. Woolley, D. Hadley, P. Landre, A. J. deMello, R. A. Mathics, and M. A. Northrup, "Functional integration of pcr amplification and capillary electrophoresis in a microfabricated dna analysis device," Anal. Chem., vol. 68, pp. 4081-4086, 1996.

[2] S. C. Jacobson, J. P. Kutter, C. T. Culbertson, and J. M. Ramsey, "Rapid electrophoretic and chromatographic analysis on microchips," Micro Total Analysis Systems '98, Banff, Canada, 1998.

[3] M. A. Northrup, B. Benett, D. Hadley, P. Landre, S. Lehewa, J. Richards, and P. Stratton, "A miniature analytical instrument for nucleic acids based on micromachined silicon reaction chambers," Anal. Chem., vol. i70, p. 918922, 1998.

[4] T. D. Boone, H. H. Hooper, and D. S. Soane, "Integrated chemical analysis on plastic microfluidic devices," Solid State Sensor and Actuator Workshop '98, Hilton Head Island, South Carolina, 1998.

[5] H. Becker and W. Dietz, "Microfluidic devices for micro-tas applications fabricated by polymer hot embossing," SPIE Conference '98, Santa Clara, California, 1998 .

[6] E. Kim, Y. Xia, and G. M. Whitesides, "Polymer microstructures formed by molding in capillaries," $\mathrm{Na}$ ture, vol. 376, p. 347, 1996.

[7] R. K. Traeger, "Nonhermeticity of polymeric lid sealant," IEEE Transactions, Parts, Hybrids and Packaging, vol. PHP-13, pp. 147-152, 1977.

[8] P. F. Man, C. H. Mastrangelo, M. A. Burns, and D. T. Burke, "Microfabricated capillarity-driven stop valve and sample injector," in International Workshop on Micro Electro Mechanical Systems (MEMS 98), Heidelberg, Germany, pp. 45-50, 1998.

[9] J. S. Rossier, M. A. Roberts, R. Ferrigno, and H. H. Girault, "Electrochemical detection in polymer microchannels," Analytical Chemistry, vol. 71, pp. 4294-4298, 1999. 